Submitted to the 1995 Particle Accelerator Conference, Dallas, Texas, May 1-5, 1995.

\title{
A Proposed NSLS X-Ray Ring Upgrade Using B Factory Technology ${ }^{*}$
}

\section{E.B. Blum, National Synchrotron Light Source, Brookhaven National Laboratory, Upton, NY 11973}

\section{ABSTRACT}

A proposed upgrade to the NSLS X-Ray Ring is described that will allow the storage of a $2.4 \mathrm{~A}, 3 \mathrm{GeV}$ electron beam using technology developed for the PEP-II $B$ factory at SLAC. In this configuration, a peak flux of greater than $10^{16}$ photons/sec/0.1\% bandwidth/5 mrad will be produced. The four existing $53 \mathrm{MHz}$ RF cavities will be replaced with eight $476 \mathrm{MHz}$ cavities. Two $952 \mathrm{MHz}$ cavities will also be used to lengthen the bunch, increasing the Touschek life-time. A copper vacuum chamber will be needed to absorb the increased synchrotron radiation and a feedback system may be needed to prevent multi-bunch instabilities.

\section{INTRODUCTION}

The third generation synchrotron radiation sources have been designed to produce high brightness beams from undulators. Some experiments may not need brightness (photons / unit time / unit energy bandwidth / unit solid angle / unit source area) as much as flux (photons / unit time / unit energy band width) which can only be provided by a high current storage ring. To meet the need for increased flux, work has already begun to raise the current in the NSLS X-Ray Ring by from 250 to $500 \mathrm{~mA}$ at the present operating energy of $2.584 \mathrm{GeV}$ [1]. A much greater increase in the flux can be obtained using technology developed for the SLAC B factory [2] to simultaneously raise the X-Ray Ring energy to $3 \mathrm{GeV}$ and the current to 2.4 Amp [3].

Fig. 1 compares the flux from the proposed upgrade to the X-Ray Ring with the ALS and the APS. Clearly, the flux from the NSLS X17, X21, and X25 wigglers exceeds that from any other source over the entire spectral range. The NSLS undulators (X1 and PSGU) also produce more flux than the third generation sources in the range from 200 to $2000 \mathrm{eV}$. In that range, the NSLS undulators are even competitive in brightness, filling in the gap between the ALS U5.0 undulator at low energy and the APS UA undulator at high energy by producing over $2 \times 10^{18}$ photons $/ \mathrm{sec} / 0.1 \%$ b.w. $/ \mathrm{mm}^{2} / \mathrm{mrad}^{2}$. This may benefit the $\mathrm{x}$ ray microscopy experiments underway at the NSLS as well as other brightness-limited soft $\mathrm{x}$-ray experiments.

After the upgrade, the X-Ray Ring will produce twenty times more synchrotron radiation power than is produced today. This qualitative change from today's conditions will place great demands on the RF and vacuum systems. The

* This work was performed under the auspices of the U.S. Department of Energy under contract DE-AC02$76 \mathrm{CH} 00016$. requirements are similar to those for the SLAC PEP-II $B$ factory. PEP-II will have two rings, one at $3.1 \mathrm{GeV}$ and the other at $9 \mathrm{GeV}$. The PEP-II RF, vacuum, and multibunch fecdback systems are adapted for the proposed $\mathrm{X}$-Ray Ring upgrade.

Other problems to be solved in the upgrade include operation of the X-Ray Ring magnets at $3 \mathrm{GeV}$ levels and rapid injection to high current. This paper will describe certain aspects of the upgrade. Enough information will be given to show the feasibility of high current operation of the NSLS X-Ray ring although a complete design will not be presented here.

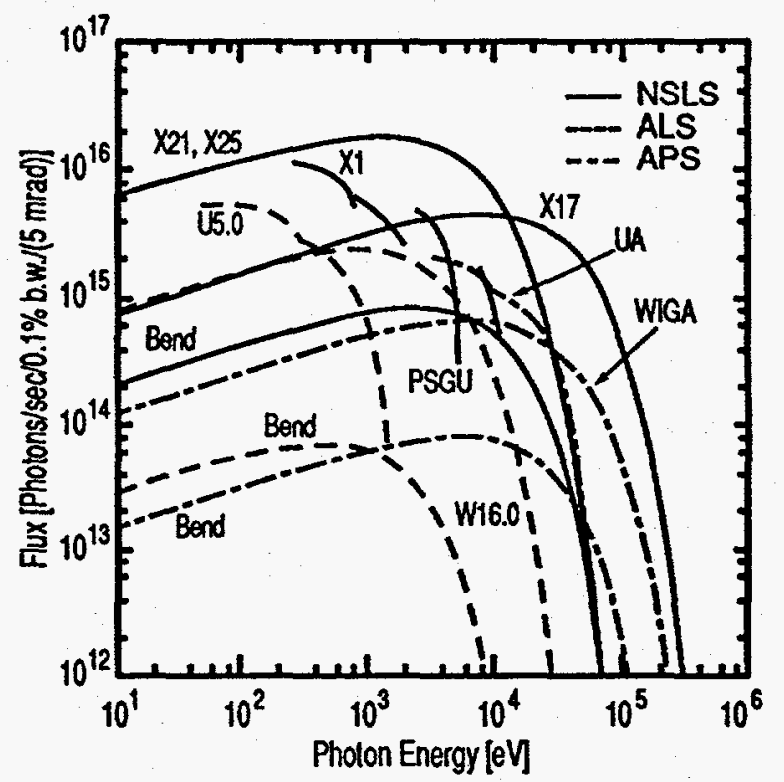

Fig.1: Comparison of the flux from various sources at the proposed upgraded NSLS X-Ray Ring ( $2.4 \mathrm{~A}, 3 \mathrm{GeV})$, the ALS $(0.4 \mathrm{~A}, 1.5 \mathrm{GeV})$, and the APS $(0.1 \mathrm{~A}, 7 \mathrm{GeV})$. (Data provided by $S$. Hulbert [4].)

\section{X-RAY RING MODIFICATIONS}

Table 1 lists major properties of both the existing and upgraded NSLS X-Ray Ring. The upgrade uses eight $476 \mathrm{MHz}$ cavities to support a $2.42 \mathrm{~A}, 3 \mathrm{GeV}$ beam. A pair of second harmonic cavities is used to lengthen the bunch from $0.73 \mathrm{~cm}$ to $2.64 \mathrm{~cm}$, providing a Touschek lifetime of 184 hours (as calculated by the program ZAP [5]). Each of the storage ring RF systems will be described in the following section.

Both upgrade designs specify 225 of the 270 buckets filled in order to maintain the same length gap in the beam as is now used to prevent ion trapping. The energy acceptance is also preserved. The horizontal emittance is scaled for the higher energy from the $2.5 \mathrm{GeV}$ value but the vertical incorporates the improved decoupling that has recently become operational [6]. 
Table 1. Major X-Ray Ring Parameters

\begin{tabular}{lcc}
\hline & Current & Upgrade \\
\hline Energy [GeV] & 2.5 & 3.0 \\
Beam Current [A] & 0.25 & 2.42 \\
Horiz. Emittance [nm-rad] & 120 & 173 \\
Vert. Emittance [nm-rad] & 1.20 & 0.29 \\
Fund. Cavity Freq. [MHz] & 52.88 & 475.92 \\
Fund. Cavity Voltage [MV] & 0.9 & 4.26 \\
RF harmonic & 30 & 270 \\
Number of Bunches Filled & 25 & 225 \\
Bunch Length [cm] & 4.33 & 2.64 \\
Synch. Rad. Loss [MeV/turn] & 0.50 & 1.04 \\
Trans. Damping Time [msec] & 4.56 & 2.64 \\
Long. Damping Time [msec] & 2.28 & 1.32 \\
Energy Acceptance & $1.82 \%$ & $1.82 \%$ \\
Synch. Freq. [KHz] & 5.91 & 35.22 \\
Touschek lifetime [hours] & 309 & 184 \\
\hline
\end{tabular}

Table 2. $476 \mathrm{MHz}$ RF System Parameters

\begin{tabular}{|c|c|c|}
\hline & & PEP-II Design \\
\hline Frequency $[\mathrm{MHz}]$ & 475.92 & 476 \\
\hline Peak Voltage $[\mathrm{MV}]$ & 4.26 & \\
\hline Harmonic Number & 270 & \\
\hline Synch. Rad. Loss [MeV/turn] & 1.04 & \\
\hline Synchronous Phase [Deg.] & 19.03 & \\
\hline Number of Cavities & 8 & \\
\hline Gap Voltage/Cavity [MV] & 0.53 & \\
\hline Cavity Gap [cm] & 22.34 & \\
\hline Gradient $[\mathrm{MV} / \mathrm{m}]$ & 2.39 & 4.5 \\
\hline Shunt Imped./Cavity $[\mathrm{M} \Omega]$ & 3.50 & \\
\hline Wall Loss/Cavity [KW] & 40.6 & 150 \\
\hline Total Wall Loss [KW] & 325 & \\
\hline Synch. Rad. Power [KW] & 2525 & \\
\hline HOM Power [KW] & 417 & \\
\hline Total Power Loss [KW] & 3266 & \\
\hline Power Loss/Cavity [KW] & 298 & \\
\hline Detuning Angle (Deg) & 88.25 & \\
\hline Refl. Power/Cavity [KW] & 4.26 & \\
\hline Input Power/Cavity [KW] & 413 & 450 \\
\hline Number of Klystrons & 4 & \\
\hline Req. Power/Klystron [KW] & 825 & 1200 \\
\hline
\end{tabular}

Table 3. Harmonic RF System Parameters

\begin{tabular}{lcc}
\hline & \multicolumn{2}{c}{ Valvo Klystron } \\
\hline Frequency [MHz] & 951.84 & 1000 \\
Peak Voltage [MV] & 2.04 & \\
Synchronous Phase [Deg.] & 4.89 & \\
Number of Cavities & 2 & \\
Gap Voltage/Cavity [MV] & 1.02 \\
Cavity Gap [cm] & 11.17 \\
Gradient [MV/m] & 9.15 \\
Shunt Imped./Cavity [M $]$ & 4.95 \\
Wall Loss/Cavity [KW] & 106 \\
Total Wall Loss [KW] & 211 & \\
Number of Klystrons & 1 & \\
Req. Power/Klystron [KW] & 211 & 400 \\
\hline
\end{tabular}

\section{A. RF SYSTEM}

The biggest obstacle to raising the X-Ray Ring's energy and current is supplying enough RF power to the beam to replace the synchrotron radiation losses. Only a limited increase in current (perhaps $1 \mathrm{~A}$ at $2.5 \mathrm{GeV}$ ) can be accomplished with the four existing $52.88 \mathrm{MHz}$ RF cavities. Instead, the upgrade will use the PEP-II single cell, copper RF cavities, operating at a frequency of $475.92 \mathrm{MHz}$. The operating frequency was chosen because it is exactly onesixth of the linac frequency, which simplifies injection timing and is close to the $500 \mathrm{MHz}$ frequency used in many other electron storage rings, requiring only small modification of existing klystron designs. Four of the $476 \mathrm{MHz}$ cavities fit in the space now occupied by two of the $52.88 \mathrm{MHz}$ cavities.

Details of the $476 \mathrm{MHz}$ RF system are shown in Table 2. Eight cavities were used in the upgrade design to stay within the PEP-II cavity's limits for gradient, wall losses, and input power (Table 2). As in the PEP-II design, one klystron is used for every two cavities. The klystron output is divided between the cavities using a magic tee. A circulator with water load is placed between each cavity and the magic tee to absorb any reflected power. The maximum power from the klystron is within the PEP-II limits.

The second harmonic system used to lengthen the bunch will have a frequency of $951.84 \mathrm{MHz}$. Properties for this system are listed in Table 3. Although the cavities have not been designed, the shunt impedance was scaled from the $476 \mathrm{MHz}$ cavities by the square root of the frequency. The peak voltage and synchronous phase were chosen for optimal bunch lengthening. It is assumed that a $400 \mathrm{KW}$, $1 \mathrm{GHz}$ Valvo klystron can be modified for the lower frequency. One klystron will be used to power both of the cavities.

\section{B. VACUUM SYSTEM}

The existing aluminum vacuum chamber in the $X$-Ray Ring can be operated safely at a maximum current of $500 \mathrm{~mA}$ at $2.5 \mathrm{GeV}$. Increasing the current and energy will have several effects including increased gas pressure, excessive chamber heating, and higher levels of radiation near the chamber. The chamber radiation has contributions from synchrotron radiation as well as from electrons striking the chamber wall. It may or may not be significant here but it has been a concern in B factory design.

Again following the example of PEP-II, the upgraded NSLS X-Ray Ring will use a copper chamber instead of aluminum. This has three advantages as a chamber material: lower photodesorption, improved thermal conductivity, and higher atomic number for improved radiation shielding. The lower photodesorption from copper permits the use of distributed ion pumps instead of the non-evaporable getter (NEG) pumps used in the third generation light sources. 


\section{DISCLAIMER}

Portions of this document may be illegible in electronic image products. Images are produced from the best available original document. 
The maximum beam current permitted by the upgrade, $2.4 \mathrm{~A}$, was determined by the synchrotron radiation heat load on the dipole chamber. At that current, the density of the radiation striking the chamber wall is $2.31 \mathrm{KW} / \mathrm{cm}^{2}$. the same as the maximum power density allowed in the PEP-II high energy ring chamber.

The pressure in the vacuum chamber at the maximum current was calculated from photodesorption of gas molecules from the chamber walls by synchrotron radiation. Desorption coefficients for copper and aluminum were obtained [7] from measurements on an NSLS VUV Ring beamline. Similar pressures of 7 to $8 \times 10^{-9}$ Torr were obtained for the existing aluminum chamber with $0.25 \mathrm{~A}$ at $2.5 \mathrm{GeV}$ and the proposed copper chamber with $2.4 \mathrm{~A}$ at 3 $\mathrm{GeV}$ for the total pumping speed of $8,880 \mathrm{~L} / \mathrm{Sec}$ that is now available. This suggests that additional pumping speed will not be needed for the upgrade.

\section{FEEDBACK}

Running a high current in 225 bunches may produce a multi-bunch instability. SLAC has designed a modular feedback system for PEP-II to damp longitudinal multibunch instabilities[8]. The system uses broad-band digital feedback, implemented on digital signal processors (DSPs) to individually control the motion of each bunch. The system is designed so that DSP modules can be added to the system as the number of bunches increases. PEP-II will require 15-20 modules to control 1658 bunches. The upgraded NSLS ring will only need 2-3 modules for 225 bunches.

\section{MAGNETS}

Most of the X-Ray Ring magnets can be operated at $3 \mathrm{GeV}$ without saturation or power supply problems except for the sextupoles and one of the four quadrupole families. These were built from the laminations designed for the $750 \mathrm{MeV}$ NSLS VUV Ring and are already saturating at $2.5 \mathrm{GeV}$. They must be redesigned for the upgrade.

\section{INJECTION}

Electrons are now injected into the X-Ray Ring at $750 \mathrm{MeV}$ before the magnets are ramped to the $2.5 \mathrm{GeV}$ operating energy. Because it is unclear if the ring can stably store $2.4 \mathrm{~A}$ at low energy, construction of a full energy injector has been considered as part of the upgrade. The injector can be built concentrically inside of the X-Ray Ring in space that is now used for storage, shops, and power supplies.

The full energy injector will consist of a $10 \mathrm{~Hz}, 3 \mathrm{GeV}$ synchrotron with a four section, $200 \mathrm{MeV}$ S-band linac for its injector. The synchrotron dipole magnets will need a peak field of $1.47 \mathrm{~T}$ in order to fit the injector into the available space. One of the $475.92 \mathrm{MHz}$ PEP-II cavities will be used in the synchrotron. The X-Ray Ring can be filled to $2.4 \mathrm{~A}$ in 24 seconds with a current of $10 \mathrm{~mA} / /$ cycle accel erated in the synchrotron.

\section{CONCLUSION}

Examination of the major accelerator systems at the NSLS X-Ray Ring shows that an upgrade to $2.4 \mathrm{~A}, 3 \mathrm{GeV}$ operation is technically feasible. The improvements needed so that the beamline components can handle the intense radiation are beyond the scope of this paper, however, studies for synchrotron radiation beamlines at the proposed CESR B-factory [9] and elsewhere show that such improvements are possible. A scientific case for the X-Ray Ring upgrade has not yet been made.

\section{REFERENCES}

[1] M.G. Thomas, R. Biscardi, W. Broome, S. Buda, R. D'Alsace, S. Hanna, J. Keane, P. Mortazavi, G. Ramirez, and J.M. Wang, Proceedings of the 1993 Particle Accelerator Conference, 1419.

[2] SLAC report, LBL-PUB-5379, SLAC-418, CALT68-1869, UCRL-ID-114055, UC-IIRPA-93-01 (1993).

[3] E.B. Blum, BNL Report BNL-49795 (1993).

[4] S.L. Hulbert and J.M. Weber, Nucl. Inst. and Meth. in Physics Research A319 (1992) 25.

[5] M.S. Zisman, S. Chattopadhyay, and J.J. Bisognano, L.B.L. Report LBL-21270, UC-28 (1986).

[6] J. Safranek and S. Krinsky, Proceedings of the 1993 Particle Accelerator Conference, 1491.

[7] C.L Foerster, H. Halama, G. Korn, M. Calderon, and W. Barletta, Vacuum, 44 (1993) 489.

[8] J.D. Fox, N. Eisen, H. Hindi, I. Linscott, G. Oxoby, L. Sapozhnikov, and M. Serio, Proceedings of the 1993 Particle Accelerator Conference, 2076.

[9] Q. Shen and D. Bilderback, SPIE Vol. 1739 High Heat Flux Engineering (1992) 191. 


\section{DISCLAIMER}

This report was prepared as an account of work sponsored by an agency of the United States Government. Neither the United States Government nor any agency thereof, nor any of their employees, makes any warranty, express or implied, or assumes any legal liability or responsibility for the accuracy, completeness, or usefulness of any information, apparatus, product, or process disclosed, or represents that its use would not infringe privately owned rights. Reference herein to any specific commercial product, process, or service by trade name, trademark, manufacturer, or otherwise does not necessarily constitute or imply its endorsement, recommendation, or favoring by the United States Government or any agency thereof. The views and opinions of authors expressed herein do not necessarily state or reflect those of the United States Government or any agency thereof. 